Research Article

\title{
Compact High-Voltage Pulse Generator for Pulsed Electric Field Applications: Lab-Scale Development
}

\author{
N. F. Kasri, M. A. M. Piah $(\mathbb{D}$, and Z. Adzis \\ Institut Voltan dan Arus Tinggi (IVAT), Universiti Teknologi Malaysia, Skudai 81310, Malaysia \\ Correspondence should be addressed to M. A. M. Piah; fendi@utm.my
}

Received 15 March 2020; Revised 20 July 2020; Accepted 8 August 2020; Published 25 September 2020

Academic Editor: Luca Maresca

Copyright (c) 2020 N. F. Kasri et al. This is an open access article distributed under the Creative Commons Attribution License, which permits unrestricted use, distribution, and reproduction in any medium, provided the original work is properly cited.

\begin{abstract}
Square wave pulses have been identified as more lethal compared to exponential decay pulses in PEF applications. This is because of the on-time which is longer causes a formidable impact on the microorganisms in the food media. To have a reliable highvoltage pulse generator, a technique of capacitor discharge was employed. Four units of capacitor rated $100 \mu \mathrm{F} 1.2 \mathrm{kV}$ were connected in series to produce $25 \mu \mathrm{F} 4.8 \mathrm{kV}$ which were used to store the energy of approximately $200 \mathrm{~J}$. The energy stored was discharged via HTS 181-01-C to the load in the range of nano to microseconds of pulse duration. The maximum voltage applied was limited to $4 \mathrm{kV}$ because it is a lab-scale project. The electrical circuit diagram and the development procedure, as well as experimental results, are presented.
\end{abstract}

\section{Introduction}

Cell electroporation therapy (EPT), genetic therapy, ultrasonic cleaning, chemical-free bacterial decontamination, and medical imaging are the examples of vast applications that require a high-voltage pulse generator which can provide pulse width in a scale of a nanosecond, microsecond, and millisecond [1-11]. However, the efficacy of these applications is highly dependent on the pulse shape, the intensity of the electric field, the number of pulses, and the electrode geometry $[12,13]$.

The effects during electroporation could be reversible or irreversible depending on the treatment intensity that causes damage to the membrane of a living cell [14-18]. In the irreversible electroporation, the cell loses its homeostasis and eventually dies if and only if the strength of the electric field applied is sufficiently intense [19]. Based on the findings, this method was used as a tool for microbial inactivation $[20,21]$. The impact of the pulsed electric field (PEF) on microbial viability has been widely studied in various types of bacteria including Gram-positive and -negative bacteria, yeast, protozoan parasites, and spores [22-29].

Because the inactivation of microbes under controlled laboratory conditions showed positive effects that can be achieved through the application of PEF, it is also used to eradicate pathogenic microbial agents from various sources of water and liquid foods with minimal effect on vitamins, taste, and food textures [23, 30-40]. Besides, the electroporation process is also employed to extract molecules from cells such as proteins from microorganisms, plasmid DNA, sugar from sugar beet cells, and oil for biodiesel [41-44].

The way to implement PEF on a substantial scale that will attract the industry is that it must be made in a continuous system. Therefore, the development of the flow process has been introduced. A continuous-type chamber with the parallel electrodes and a set of fluid handling systems have been included together in the PEF treatment system other than a pulse generator and high-voltage power supply. In PEF flow applications, electroporators must meet specific requirements and they must be designed so that the system can provide high-voltage and high-current pulses. Although a commercial electroporator is capable of providing high electric field intensity in the order of $10 \mathrm{kV} / \mathrm{cm}-100 \mathrm{kV} / \mathrm{cm}$ with continuous operation and high repetition rate, it does not fit in the studies on bacterial inactivation or various substances extraction from cells [45].

For this reason, the aim of this study was therefore to develop a square-wave high-voltage pulse generator that 
was particularly built for the laboratory scale. It has been equipped with features that enable it to operate over a wide range of pulse parameters (ns- $\mu$ s) which is not available in the commercial electroporators where it has been optimized for specific parameters [46]. For the current status, many commercial devices limit their output pulse voltage amplitude up to $3 \mathrm{kV}$ [47] and refer to the fact that the electroporation process demands certain threshold behavior and higher voltage application is desirable to be met.

To fulfill the purpose, the capacitor-discharge technique was employed. This method has been proven to increase the control of electrical field parameters [48]. Apart from that, the applied voltage has been increased up to $4 \mathrm{kV}(\max )$. For the high-voltage pulse generation, a compact power MOSFET (metal-oxide-semiconductor field-effect transistor) was introduced to connect and disconnect the power lines from the load while delivering the intended pulse width which is within nano-microsecond range. All the components used were small in size to yield compact high-voltage pulse generation units, yet they are reliable and robust for PEF applications. Compact features were integrated to make the end product lighter and portable.

\section{Working Principle}

The working principle of the proposed circuit (Figure 1) is quite straightforward. $V_{\text {source }}$ aims to provide high voltage to the system. Once the voltage is applied, then the capacitor arrangement will be charged to full scale. It reacts as a buffer by storing energy and will always be in the standby mode before being discharged. $V_{\text {pulse }}$ is used to trigger $Q_{1}$ where the snubber circuit is connected parallel to it (limiting $\mathrm{d} I / \mathrm{d} t$ and $\mathrm{d} V / \mathrm{d} t$ as well as reducing voltage and current spikes). The moment Q1 is triggered, there will be a connection between the power line and the load; thus, energy stored in the capacitor array is discharged via $Q 1$ to the load.

$R_{\text {line }}$ and $L_{\text {line }}$ are included to mimic the inherent parasitic components in the actual circuit. It is crucial to consider these as they can trigger instability such as the ringing effect on the output pulse voltage. Besides, their presence also affects the rise and fall time of the output pulse. Therefore, a proper adaptation of the snubber circuit can help reduce their impact as they cannot be eliminated practically. In practice, parasitic components can be reduced by making the copper trace on PCB (printed circuit board) wide and short.

$R_{L}$ and $R_{L 1}$ are connected in parallel to the load intended to limit the current flow. It divides the current so that the load will only receive a certain amount. This is due to the limitations of the Q1 specification which does not allow excessive current flow. Besides, it suppresses the overshoot of the output pulse voltage across the load during turn-on time while escalating the minimum load that can be handled by the generator. The treatment chamber is made equivalent to the $\mathrm{RC}$ circuit connected in parallel which represents charge carrying conduction and dielectric polarization, respectively.

\section{Simulation Setup}

For the simulation study, Multisim 14.0 software by NI (National Instrument) was employed to design and test the proposed circuit (Figure 1). To get satisfactory results, the SPICE (Simulation Program with Integrated Circuit Emphasis) model for $Q 1$ has been modified to suit the required specifications. Level 1 model was applied to signify Q1, and the summary of the SPICE model parameters used is shown in Table 1.

\section{Hardware Development}

The objective of this research was to design and build a $0-4 \mathrm{kV}$ square-wave pulse generator which is compact and equipped with variable pulse durations of ns to $\mu$ s. Regarding the frequency of the pulse, it was also made variable where it can be set as low as $125 \mathrm{~Hz}$ to as high as $1 \mathrm{MHz}$. The practical development process of the pulse generator can be breakdown into four major parts: (1) variable high-voltage source which converts the utility of AC voltage to a DC high voltage, (2) energy storage system to store the energy by charging the capacitor, (3) switching block to generate high-voltage pulses, and (4) parallel-plate treatment chamber (continuous mode) that not only merely houses the electrode but also houses the treated media (liquid food).

4.1. High-Voltage Source. To achieve the pulse generator that has portable features, it must be designed in a compact size. Since the pulse generator needs a high voltage to operate, it must be equipped with a high-voltage source where a transformer is commonly employed. This, however, will cause the pulse generator to be heavy, bulky, and consume space. To solve this issue, there are two techniques available: (1) by using a DC-DC converter which can convert a lower DC voltage to a higher DC voltage, and this method, however, is commonly costly, and (2) by employing a flyback transformer to obtain high voltage as per the demand due to its specification which is smaller and lighter compared to the laminated core transformer. Figure 2 shows the high-voltage source used in this study.

4.2. Energy Storage. Typically, high-voltage sources will have low current ratings $(<50 \mathrm{~mA})$ because it is impossible to have high voltage and high current at the same time continuously. Applying it directly to the load will result in a voltage drop as the load requires more power and usually low resistance. Thus, more intake of current from the source is needed to offset the load. To overcome this, a capacitor-discharge technique was introduced in this study (Figure 3). The purpose is to store energy during charging, and while operation, it provides an adequate amount of energy to the load. Besides, it causes voltage and current to be more stable throughout the entire process.

$\mathrm{C}_{\text {bank }}$ is the capacitor bank that contains several units of a capacitor that is connected in series. The employment of the resistors in parallel to each capacitor used is to balance the voltage. This will avoid the condition of undercharging and 


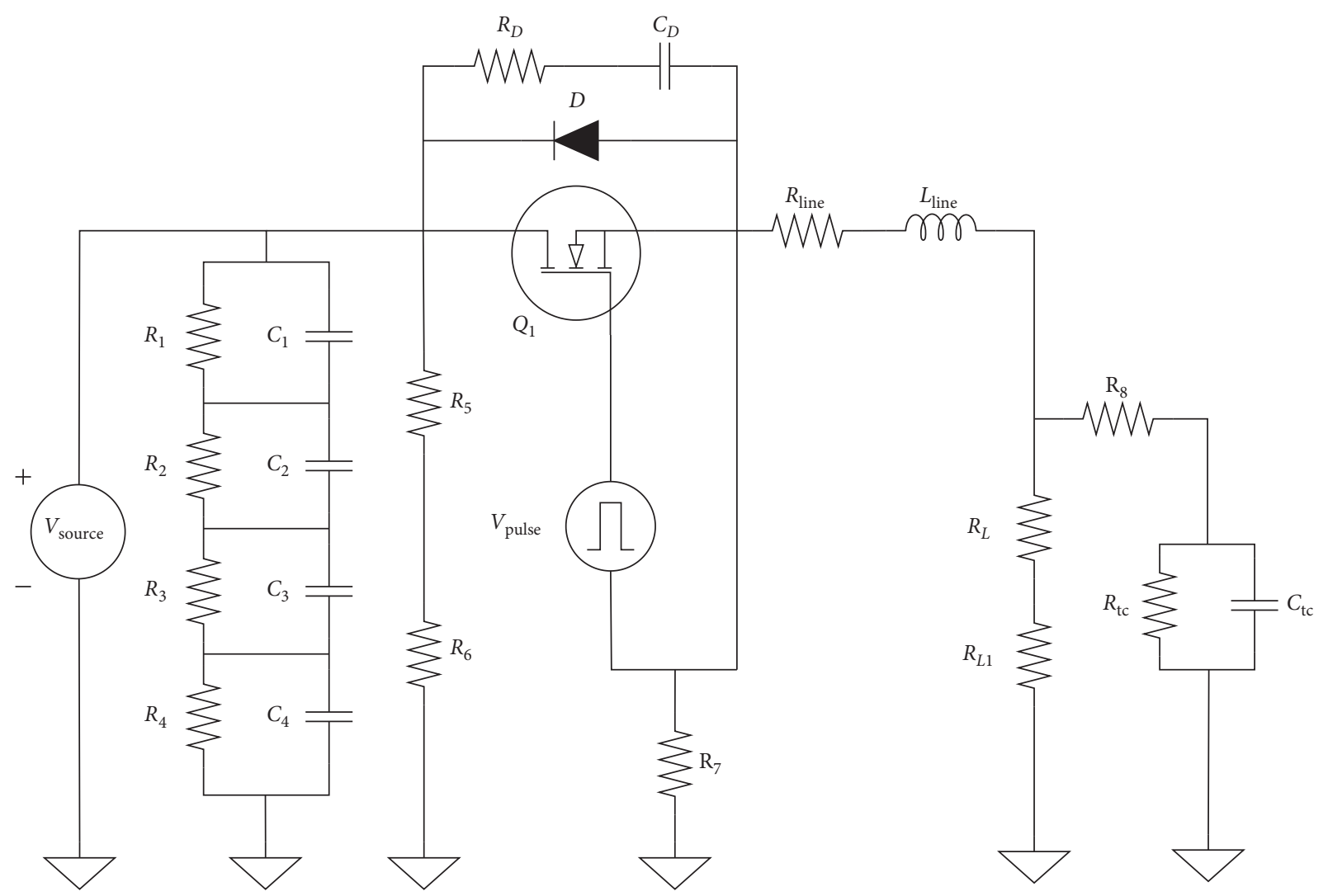

FIGURE 1: The proposed circuit implementing the capacitor-discharge technique to generate square-wave pulse.

TABLE 1: Summary of the SPICE model parameters.

\begin{tabular}{lcc}
\hline Spice parameter & Value & Denotation \\
\hline Drain-source voltage & $7 \mathrm{kV}$ & $V_{\mathrm{DS}}$ \\
On resistance & $0.06 \Omega$ & $R_{\mathrm{DS}}$ \\
Drain current (continuous) & $6 \mathrm{~A}$ & $I_{\mathrm{D}}$ \\
Drain current (pulse) & $12 \mathrm{~A}$ & $I_{\mathrm{DP}}$ \\
Zero bias gate threshold & $3.65 \mathrm{~V}$ & $V_{\mathrm{TO}}$ \\
Channel length modulation & $0.003 \mathrm{~V}^{-1}$ & lambda \\
G-D capacitance & $0.37 \mu \mathrm{F}$ & $C_{\mathrm{DG}}$ \\
G-S capacitance & $5.59 \mu \mathrm{F}$ & $C_{\mathrm{GS}}$ \\
Junction oxide capacitance & $0.43 \mathrm{nF}$ & $C_{\mathrm{JO}}$ \\
Junction grading coefficient & 0.45 & $M$ \\
Junction voltage drop & $0.5 \mathrm{~V}$ & $V_{\mathrm{J}}$ \\
Leakage current & $3.41 \mathrm{nA}$ & $I_{\mathrm{S}}$ \\
Transconductance & 18.8 & $K_{\mathrm{P}}$ \\
\hline
\end{tabular}

overcharging experienced by each capacitor. The following equation can be used to estimate the resistor value:

$$
R=\frac{\left(N V_{\max }-V_{\mathrm{app}}\right)}{0.0015 C V_{\mathrm{app}}},
$$

where $N$ is the number of the capacitor in series, $V_{\max }$ is the maximum allowable voltage on each capacitor, $V_{\text {app }}$ is the applied voltage across the entire $C_{\text {bank }}$, and $C$ is the individual capacitance in $\mu \mathrm{F}$. Typically, the resistor value will be in the range of $\mathrm{M} \Omega$. This resistor implementation prevents the self-charging phenomenon in each capacitor due to the dielectric memory effect.

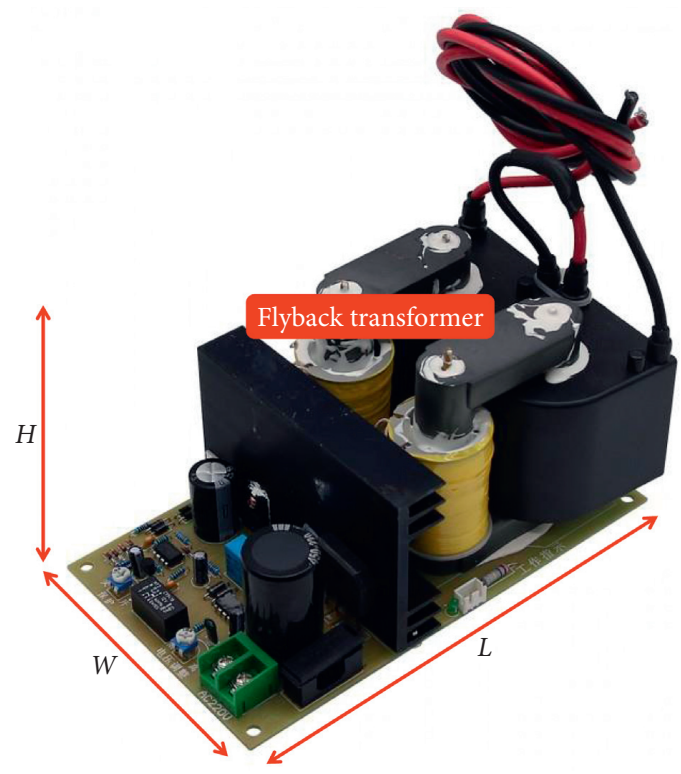

FIgUre 2: Model CX-300 of high-voltage source employed in this study. Two units of a flyback transformer were used to obtain $30 \mathrm{kV}$ ( $\max )$, but still it is small in size. The dimension is $240 \mathrm{~mm} \times 145 \mathrm{~mm} \times 108 \mathrm{~mm}(L \times W \times \mathrm{H})$.

4.3. Switching Block. To have a pulse amplitude in a few $\mathrm{kV}$, switching devices should be able to operate under highvoltage conditions. The current technology allows this to 


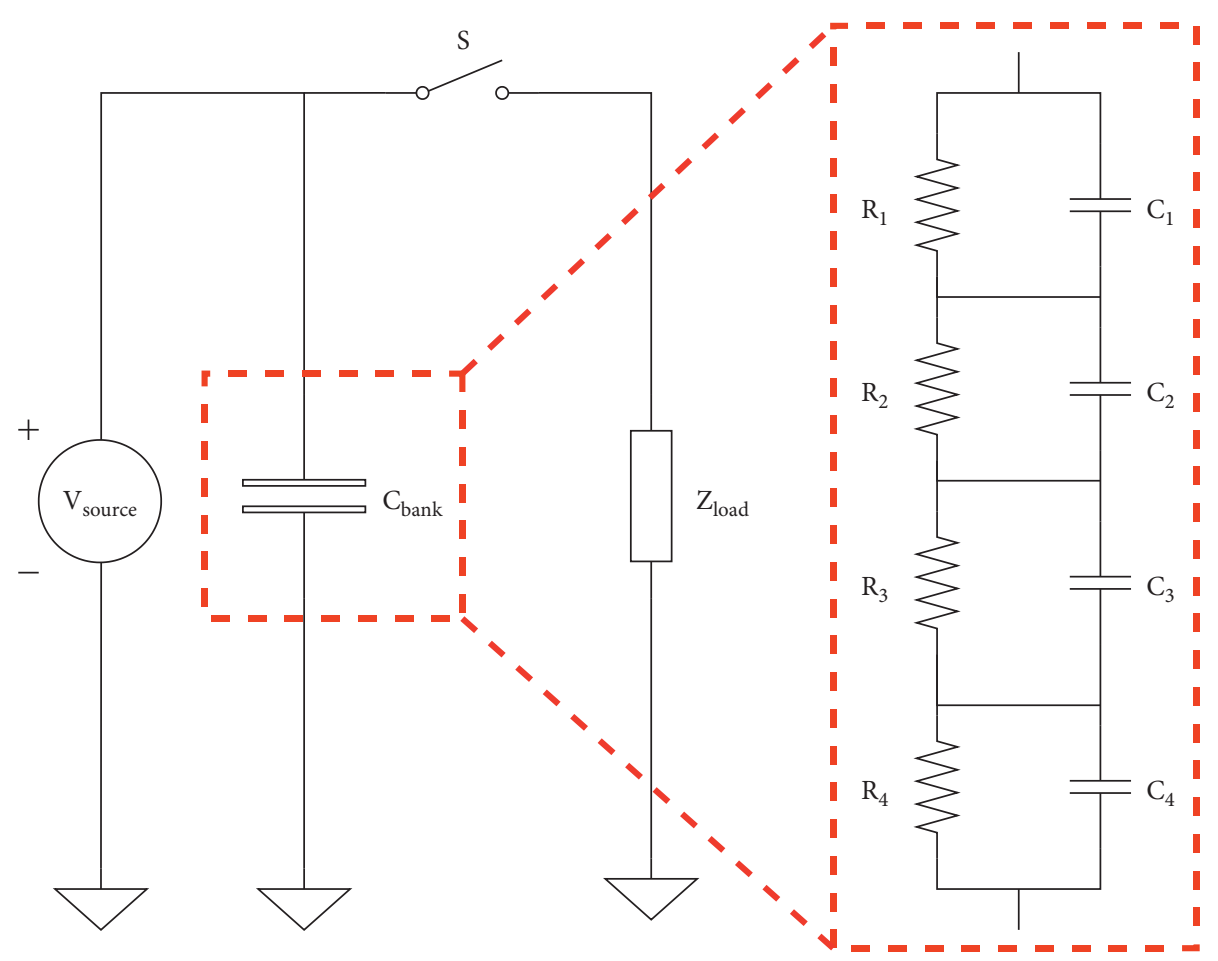

FIGURE 3: The implementation of the capacitor-discharge method to generate a square-wave pulse.

happen by the means of implementing several available techniques: single-unit device or stacked devices. In a stacked device, several MOSFETs are connected in series to accommodate the high voltage applied to it [49-52]. However, this technique has drawbacks that lie in its complexity of controlling and voltage sharing for each device. If one of the MOSFETs is damaged due to overvoltage, then the whole system will be shut down [53].

The way to solve this problem is by implementing a single unit device; in this case, the HTS 181-01-C MOSFET manufactured by Behlke Power Electronic (Germany) is implemented. This switch has features that can withstand high voltage up to $18 \mathrm{kV}$ with pulsed currents up to $12 \mathrm{~A}$. However, special efforts need to be made to fix the problems of pulse distortion, ringing effects, and overvoltage and overcurrent transient processes due to nonmatch loads and inherent parasitic components in the actual circuit to achieve a reliable generation of output pulse with flexible pulse parameters. Figure 4 shows the compact fast highvoltage transistor switch using MOSFET technology.

It was manufactured in a compact design, that is, small, light, and robust. Moreover, it can be easily controlled by feeding an auxiliary $+5 \mathrm{Vdc}$ to wake it up and can accept a TTL-compatible signal. The control signal of at least $25 \mathrm{~ns}$ duration must be supplied to the control terminal of the switch, and it can be any positive going pulse with $2-10 \mathrm{~V}$ amplitude. This means that this device is capable of delivering a nanosecond pulse width with a recovery time of 150 ns after each switching cycle.

4.4. Treatment Chamber. The treatment chamber is not merely used to store the liquid food but also functioned to

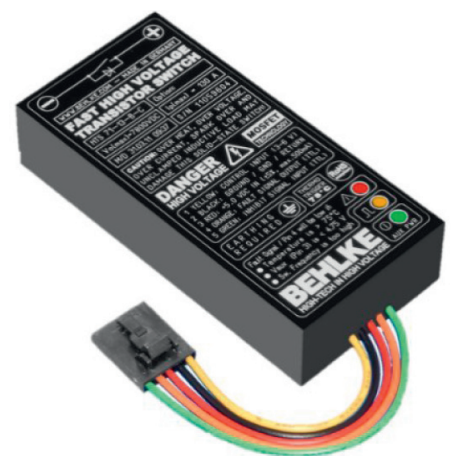

FIgURE 4: The compact series of the fast high-voltage transistor switch using MOSFET technology by Behlke power electronic.

house the electrode which was separated by the insulator. The electrode arrangement plays an important role to determine the uniformity of the electric field formation. Fundamentally, there are three configurations of an electrode: parallel, coaxial, and colinear. Parallel electrode arrangement yields the most uniform electric field formation, while coaxial arrangement yields the most nonuniform electric field development due to its dependency on the radius. Figure 5 shows the treatment chamber used in this study.

According to Figure 5, the treatment chamber has been designed in a continuous mode, and the electrode has been arranged in parallel. This can enhance the rate of microorganism inactivation compared to the static mode [54], and uniform electric field distribution can be attained between electrodes. The treatment gap was set at $2 \mathrm{~mm}$, while the effective area of electrodes was determined at $9 \mathrm{~mm}^{2}(3 \mathrm{~mm}$ 


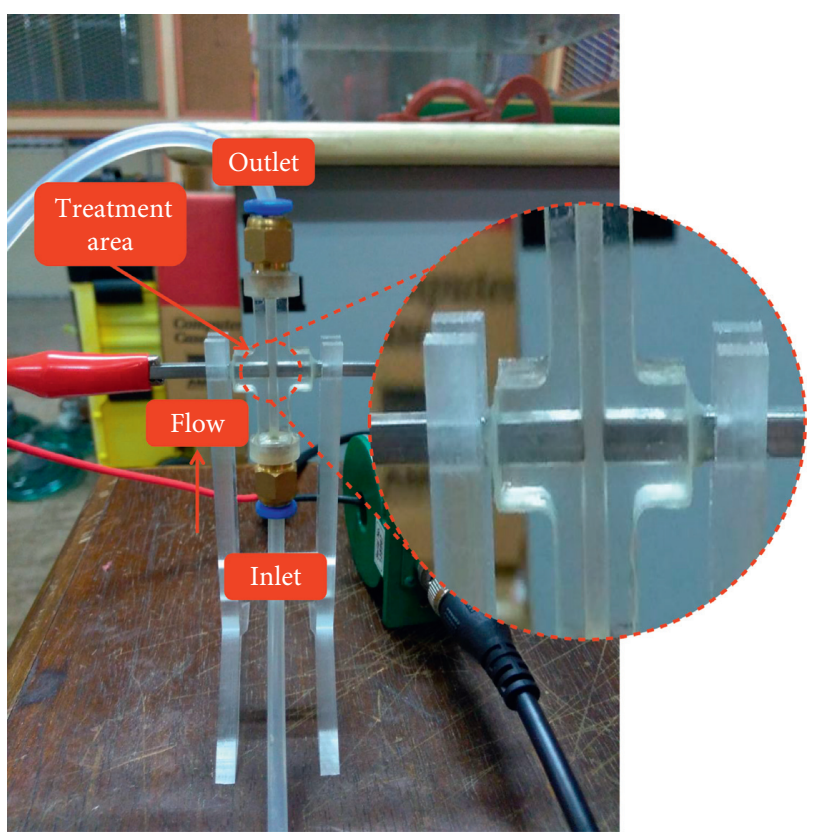

FIGURE 5: Parallel electrode treatment chamber in continuous type. The flow begins from bottom to top and is influenced by gravity acceleration.

each side); thus, a treatment volume of approximately $18 \mathrm{~mm}^{3}$ is yielded for each processing. With the max output voltage applied $(4 \mathrm{kV})$, the field strength is expected to be $20 \mathrm{kV} / \mathrm{cm}$ across the treatment area and it is sufficient to cause disasters for foodborne pathogens and spoilage microorganisms.

\section{Compact High-Voltage Pulse Generator}

By assembling all the relevant components, a compact highvoltage pulse generator was successfully constructed as shown in Figure 6(a). The dimensions of the pulse generator are also compacted to $280 \mathrm{~mm} \times 200 \mathrm{~mm} \times 170 \mathrm{~mm}$ $(L \times W \times H)$ for easy carrying. Figure 6(b) shows the preparation for the practical test. Regarding testing, it was performed in the laboratory at ambient temperature, and the travel of liquids in silicon tubes was driven by the use of peristaltic pumps. The pump speed can be adjusted to change the flow rate of the liquid which subsequently intervenes in temperature distribution across the treatment area.

The current transducer as shown in Figure 6(b) was implemented to obtain current across the treatment area. This technique of sensing is commonly known as indirect current sensing. It uses the concepts of Ampere's and Faraday's laws to get an induced voltage over the loop placed around the wire. The amplitude of the induced voltage is proportional to the current flow with minor losses, and by applying proper amplification signal, it is then converted into a standard electrical signal which is useful. In this study, $1 \mathrm{~V}$ produced by the current transducer is equivalent to $1 \mathrm{~A}$, thus, making the measurement process more convenient.

\section{Results and Discussion}

\subsection{Simulation Results}

6.1.1. Without Snubber Circuit. Before assessing the proposed circuit, a set of testing parameters should be determined as shown in Table 2. This was done to ensure that the simulation study is done correctly and thoroughly to ensure that the problems caused by the parasitic components can be solved well. Besides, the properties of the generated pulse can also be assessed from the perspective of the pulse amplitude, pulse width, and rise and fall time. This is crucial to be accomplished because, subsequently, it will be a benchmark for practical testing.

Figure 7 shows the simulation results with the influence of $L_{\text {line }}$ as a stray inductance that is expected to exist in the circuit, while $R_{\text {line }}$ was made permanent due to its insignificant effect. Regarding the voltage applied, pulse width, and load, they were set to $4 \mathrm{kV}, 500 \mathrm{~ns}$, and $680 \Omega$, respectively. Note that the snubber circuit was removed during the testing to observe the impact of stray inductance on the outcomes.

The output pulses of $500 \mathrm{~ns}$ and 5.48 A were successfully simulated according to the parameters scheduled in Tables 1 and 2 , respectively. It can be seen that the pulse shape was influenced dramatically by the presence of $L_{\text {line }}$. When the stray inductance is set high at $50 \mu \mathrm{H}$, the oscillation during the transient process has a high amplitude up to $20 \%$ of the pulse due to high $\mathrm{d} I / \mathrm{d} t$. This amplitude is expected to be higher when higher stray inductance value is set. Due to the transient time relative to the pulse width, its presence is unacceptable in PEF applications.

Stray inductance was also found to affect the switching dynamics of MOSFET, especially during turn-off transient. Figure 8 shows the measured voltage of the drain-to-source of the MOSFET. The results obtained indicate that $L_{\text {line }}$ causes a dangerous flyback voltage when the high current is turned off fast. Due to the capability of the MOSFET that can switch off high current within a nanosecond, the presence of stray inductance must be treated as a substantial source of danger.

As can be seen, the height of the flyback voltage induced during turn-off is approximately $50 \%$ of the pulse at the time the stray inductance was set to $50 \mu \mathrm{H}$ due to high $\mathrm{d} I / \mathrm{d} t$. It can be estimated by multiplying the value of inductance $(L)$ with the instantaneous rate of current change $(\mathrm{d} I / \mathrm{d} t)$. Depending on $L$ and $\mathrm{d} I / \mathrm{d} t$, sometimes the voltage produced can reach up to thousands of volts. For instance, given a copper trace with an inductance of $200 \mathrm{nH}$ at a turn-off current of $100 \mathrm{~A}$ and a turn-off time of $10 \mathrm{~ns}$, the resulting flyback voltage is as high as $2 \mathrm{kV}$. Therefore, this large amount of voltage must be suppressed properly; otherwise, it should be considered and added to the operating voltage and if it exceeds the set limit, then the risk of MOSFET damage is high.

6.1.2. With Snubber Circuit. The problems encountered during the MOSFET switching as mentioned in Section 6.1.1 can be reduced by utilizing the classic clamp circuit that is 

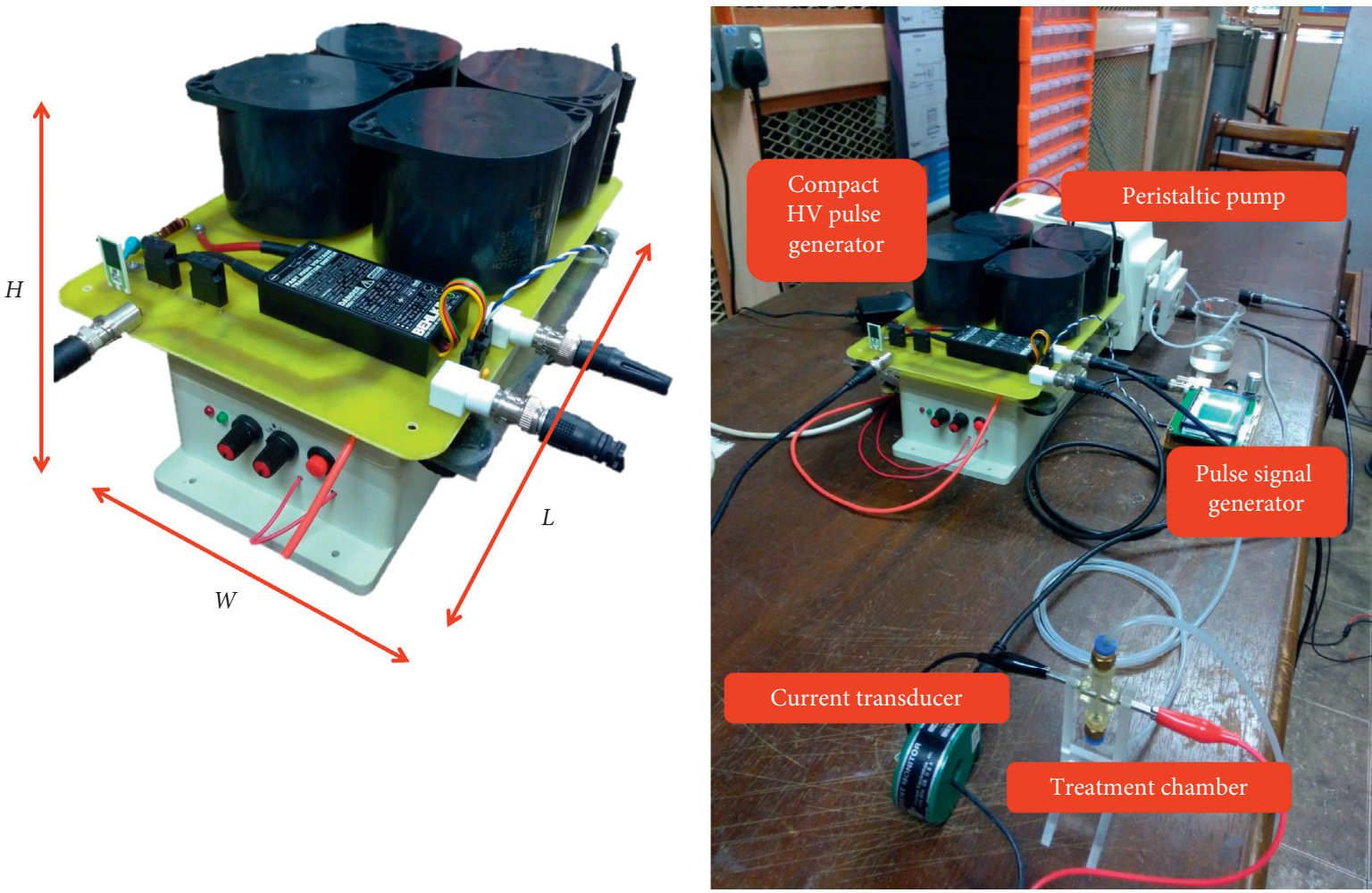

(a)

(b)

FIGURE 6: The complete unit of the compact high-voltage pulse generator developed in this study: (a) the dimension of the pulse generator and (b) practical test setup.

TABLE 2: A set of testing parameters for the simulation study.

\begin{tabular}{llll} 
Amplitude $(\mathrm{kV})$ & Pulse width (ns) & Frequency $(\mathrm{Hz})$ & Load $(\Omega)$ \\
\hline $0-4$
\end{tabular}

\begin{tabular}{llll}
$0-4$ & $125-2000$ & 125 & $250-10 \mathrm{k}$ \\
\hline
\end{tabular}

RC-snubber. It was seen as suitable for high-voltage circuitry as it is easy to build and uses only passive components. To apply, the RC-snubber must be connected in series and placed directly over the switch terminals as depicted by $R_{D}$ ad $C_{D}$ in Figure 1. Regarding the optimum values, it should be determined empirically via a simulation study. Figures 9(a) and 9(b) show the results obtained after the RCsnubber circuit was implemented.

The impact of the presence of the RC-snubber circuit was obvious in preserving the pulse shape of the output pulse from oscillation during the transient process. The oscillation at the time of turn-off was successfully suppressed for the output pulse as shown in Figure 9(a), and flyback voltage was greatly reduced while turning off the MOSFET as depicted in Figure 9 (b). $R_{D}$ was set to $10 \Omega$ to set the current limit, while $C_{D}$ was tested with a different capacitance to find the optimum value. Other parameters such as voltage amplitude, pulse width, load impedance, and frequency remained unchanged.

According to Figures 9(a) and 9(b), the optimum values for $R_{D}$ and $C_{D}$ were $10 \Omega$ and $200 \mathrm{pF}$, respectively, but since $220 \mathrm{pF}$ is more readily available in the local market, the value is selected. These values were chosen because of their influence in maintaining the output pulse shape and switching dynamics of the MOSFET without critically affecting the switching speed. The upper left corner of the output pulse was also preserved without curving as shown in Figure 7. This indicates that the implementation of the RCsnubber circuit only affects turn-off time without affecting turn-on time. Table 3 shows a summary of the parameters used in the simulation study.

\subsection{Practical Results}

6.2.1. Output Waveform of the Compact High-Voltage Pulse Generator. For practical testing, a salt solution with a conductivity of $1.95 \mathrm{mS} / \mathrm{cm}$ was used in this study, thus, producing a load impedance of approximately $1.14 \mathrm{k} \Omega$ when enclosed in the treatment area at ambient temperature. However, during processing, this value decreases because of Joule heating as conductivity is a temperature-dependent parameter. The properties of the pulses tested are shown in Table 4 . Note that only the pulse widths were made to vary, while the other parameters remain the same.

As expected, the pulse amplitude for all the pulse properties tested was $4 \mathrm{kV}$, and the current through the salt solution was approximately $5.48 \mathrm{~A}$. The pulse width was obtained according to Table 4. Figures 10(a) and 10(b) show the results attained during the practical test and have been compared with the simulation results for validation 


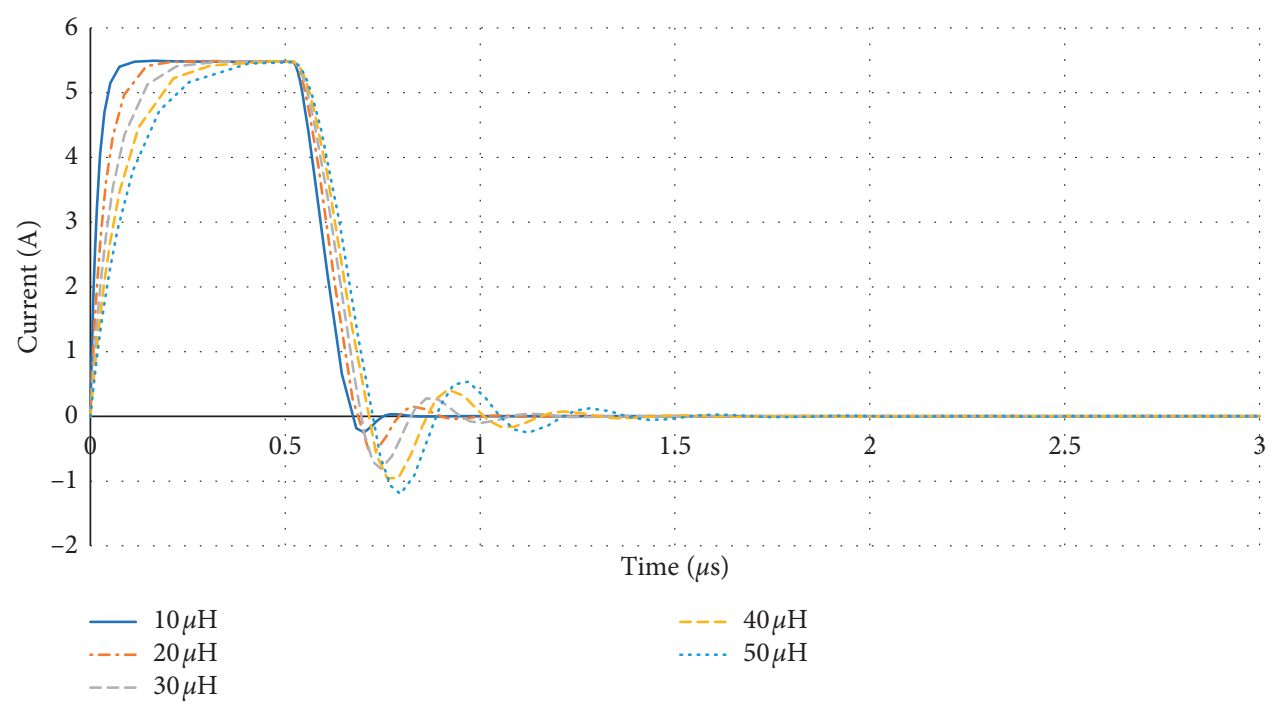

Figure 7: The effect of $L_{\text {line }}$ on the output pulse.

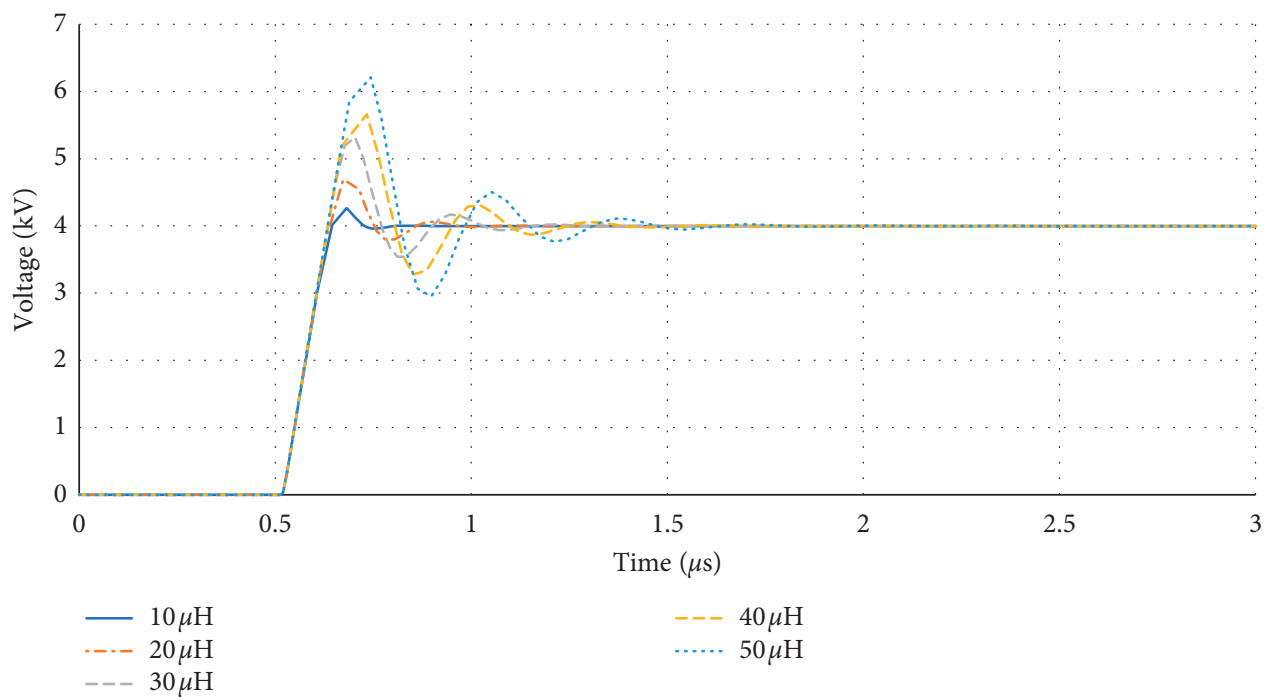

FIGURE 8: Switching dynamics of MOSFET influenced by $L_{\text {line }}$ during turn-off.

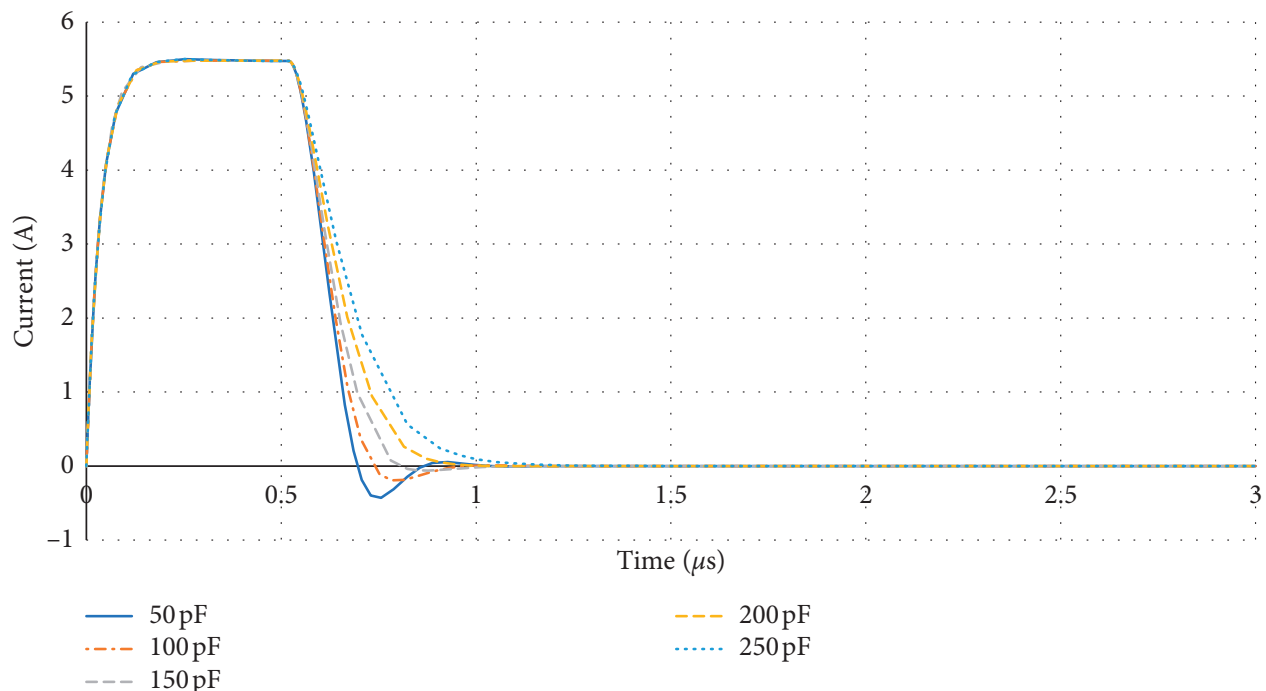

(a)

FIGURE 9: Continued. 


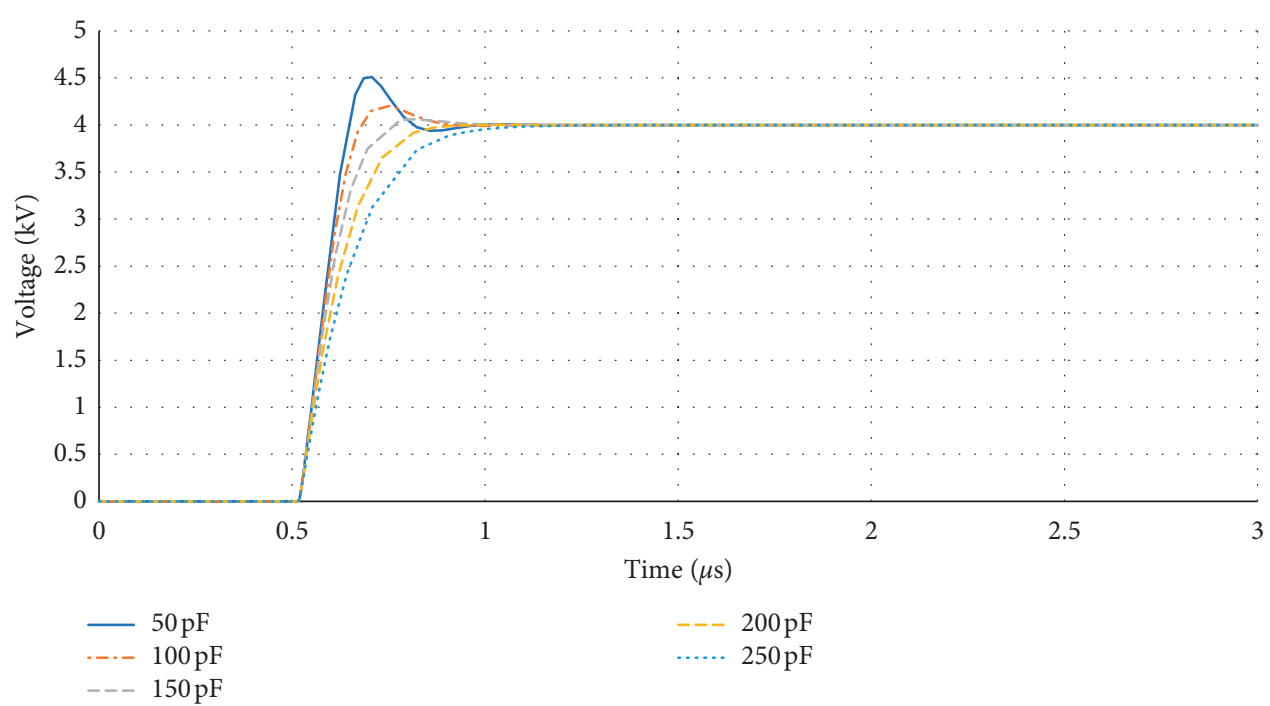

(b)

Figure 9: The effect of the RC-snubber circuit on (a) output pulse and (b) switching dynamics of MOSFET. Note that the stray inductance was set higher, i.e., $20 \mu \mathrm{H}$.

TABLE 3: Summary of the parameters used in the simulation study.

\begin{tabular}{lr}
\hline Parameters & Value \\
\hline$C 1-C 4$ & $100 \mu \mathrm{f}$ \\
$R 1-R 4$ & $1.2 \mathrm{M} \Omega$ \\
$R_{D}$ & $10 \Omega$ \\
$C_{D}$ & $220 \mathrm{pF}$ \\
$R_{\text {line }}$ & $247 \mu \Omega$ \\
$L_{\text {line }}$ & $20 \mu \mathrm{H}$ \\
$R_{L}, R_{L 1}$ & $1 \mathrm{k} \Omega$ \\
$R_{t c}$ & $680 \Omega$ \\
$C_{t c}$ & $0.01 \mathrm{pF}$ \\
\hline
\end{tabular}

TABLE 4: The properties of the pulse used in practical testing.

\begin{tabular}{lccc}
\hline Pulse amplitude $(\mathrm{kV})$ & Pulse width $(\mathrm{ns})$ & Frequency $(\mathrm{Hz})$ & Pump speed (rpm) \\
\hline 4 & 500 & 125 & 20 \\
& 1000 & & \multirow{2}{*}{. } \\
\hline
\end{tabular}

${ }^{*}$ rpm: revolution per minute.

purposes. As can be seen, both results are in good agreement with insignificant differences.

According to Figures 10(a) and 10(b), the slight difference is due to the influence of parasitic components inherent in the actual PCB. As for the copper trace, it was made wide and short as suggested to minimize the existence of stray inductance. Since the discrepancy between both results is slim (for all three regions: turn-on, plateau, and turn-off), i.e., $<10 \%$, the effect of stray inductance was significantly reduced mainly by the implementation of the RC-snubber circuit as well as the wide and short copper trace.

From the two results that have been described, it can be concluded that the proposed circuit has successfully passed the prove-of-concept stage because it can produce the intended pulse, while the RC-snubber network has successfully proven its function to limit switching voltage and reduce oscillations. This is further strengthened by the finding that the two results are comparable although there are slight differences. Thus, the simulation model for the compact high-voltage pulse generator is in acceptable compliance with the practical findings data and is a strong argument to the validity of this study.

6.2.2. Electric Field Distribution. As expected, the electric field distribution in the middle of the treatment zone is uniform. It has been proved via numerical simulation (using COMSOL Multiphysics ${ }^{\circledR}$ ) by solving the law of charge conservation. The treated media were represented by the salt 


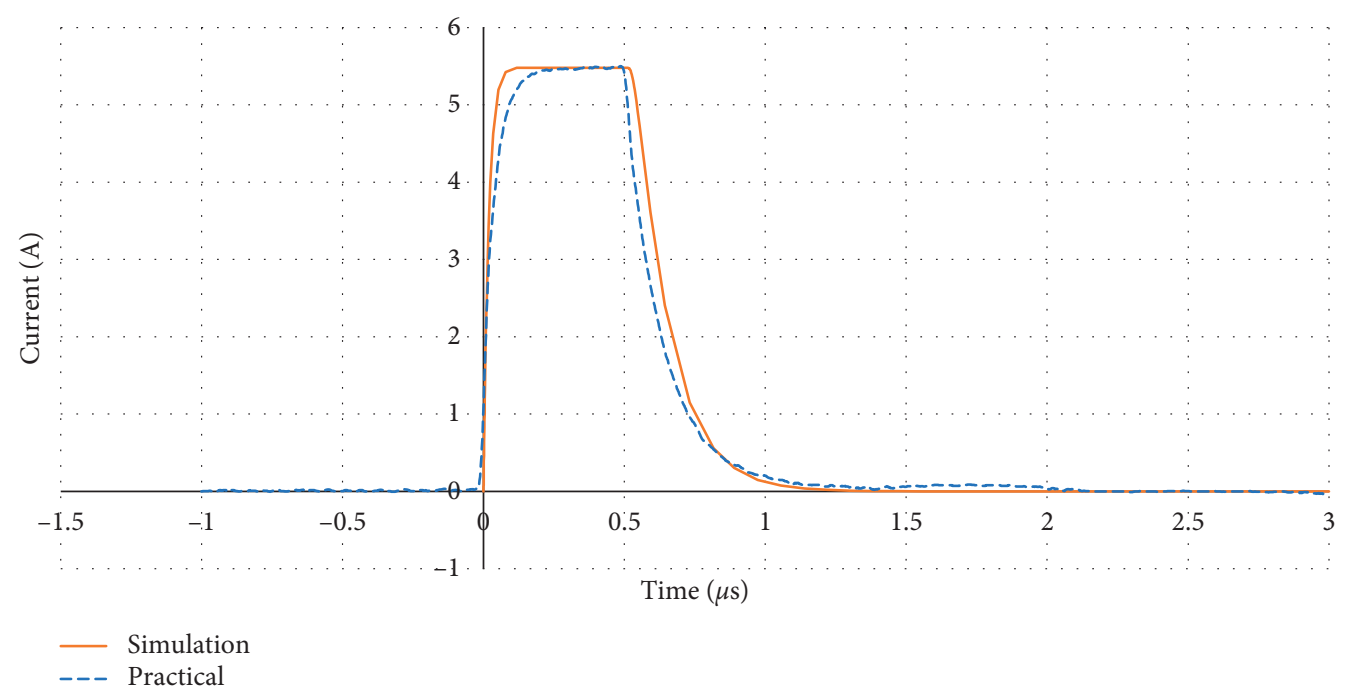

(a)

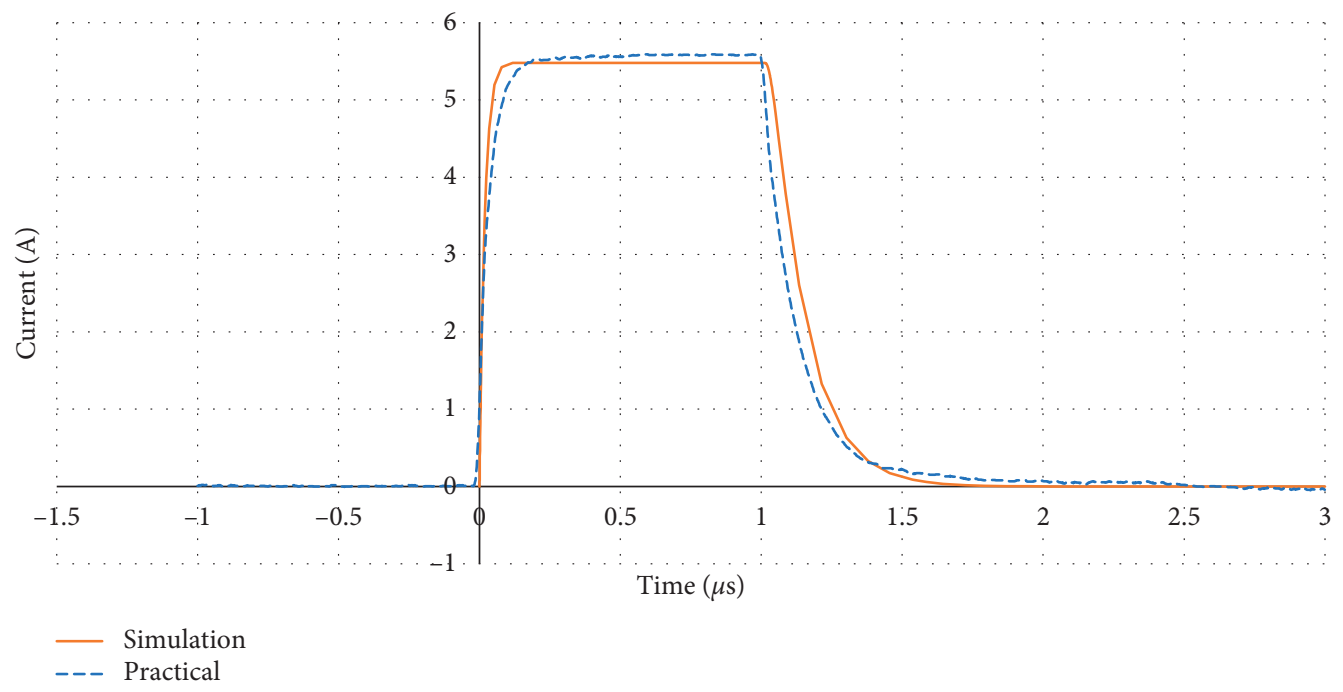

(b)

FIgURE 10: The comparison between simulation and practical results according to the pulse properties shown in Table 1 . (a) 500 ns pulse width and (b) $1000 \mathrm{~ns}$ pulse width.

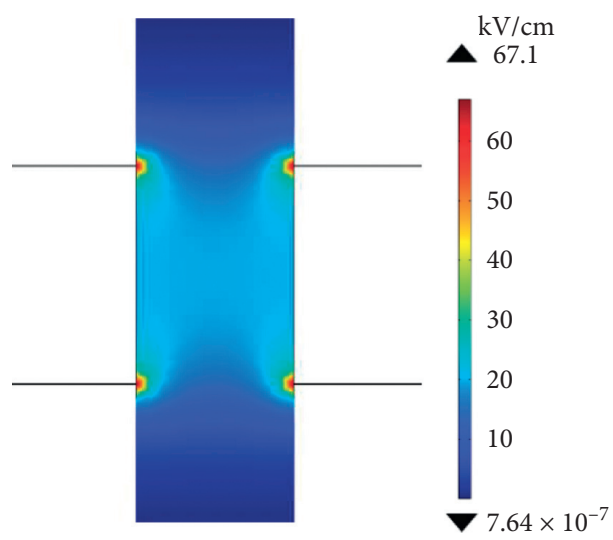

(a)

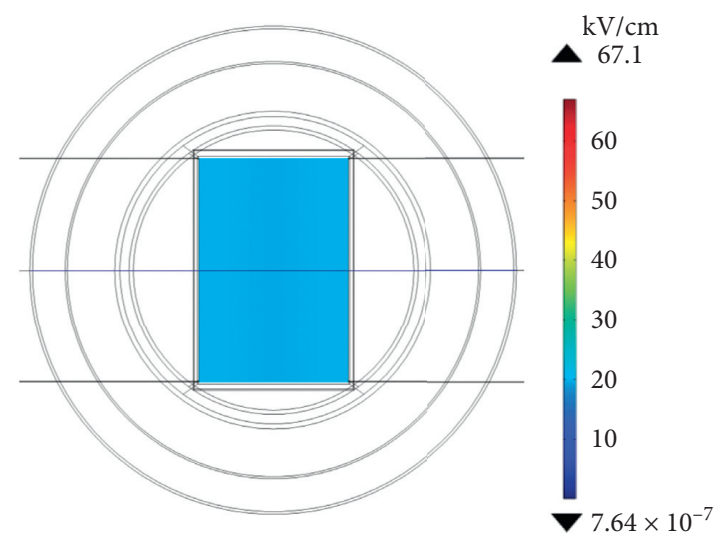

(b)

FIGURE 11: Electric field profiles that have been predicted in the treatment zone. The liquid is moving from bottom to top and is influenced by the gravitational acceleration constant of $9.81 \mathrm{~m} / \mathrm{s}^{2}$. (a) The view was taken from the coronal plane. (b) The view was taken from the transverse plane. 
solution with a conductivity of $1.95 \mathrm{mS} / \mathrm{cm}$, and the applied voltage was $4 \mathrm{kV}$. The details on the electric field distribution are depicted in Figures 11(a) and 11(b).

Refer to Figure 11(a), there was local electric field strength enhancement of approximately $>50 \mathrm{kV} / \mathrm{cm}$ being spotted mainly at each edge of the electrode. This phenomenon is due to the sharp corner at the edge of the electrode which results in a high accumulation of charges. On the contrary, the view that was taken on the transverse plane as shown in Figure 11(b) illustrates the uniformity of electric field distribution across the treatment zone. The strength of the field has been recorded high, i.e., approximately $20 \mathrm{kV} / \mathrm{cm}$ which is enough to be implemented in the PEF application.

\section{Conclusions}

The proposed circuit (Figure 1) has managed to generate the intended pulses as planned-capable of producing nanosecond and microsecond pulse width which is represented by $500 \mathrm{~ns}$ and $1000 \mathrm{~ns}$ pulse, respectively, as depicted in Figures 10(a) and 10(b). This statement is further strengthened when the results obtained from simulations and practical studies show minimal discrepancies. This indicates that the concept that is trying to be proven has been successfully achieved. Therefore, the compact high-voltage pulse generator that has been developed in this study is ready to perform as an electroporator for PEF applications.

Regarding the final cost, it was roughly estimated as less than USD2500, which when compared to the price of the commercial electroporators (usually several thousand USD) is still quite inexpensive with such high-end specifications. Interestingly, all the components used are upgradable including its firmware just to cope with the emerging demand in the future if needed. For fully functioning, the voltage and the pulse width can be altered from 0 to $4 \mathrm{kV}$ and $125 \mathrm{~ns}$ to $5 \mu \mathrm{s}$, respectively. Also, it supports a wide range of load impedance starting from $250 \Omega$ to $10 \mathrm{k} \Omega$ and above.

The treatment chamber design used in this study as depicted in Figure 5 seems to provide uniform dissemination of an electric field across the treatment zone as illustrated in Figures 11(a) and 11(b). With the help of the finite element method (FEM), the formation of electric field strength enhancement at the electrode edges can be predicted. Besides, the treatment chamber has been designed in a continuous mode that intended to increase the inactivation rate of the microorganism and distribute the temperature evenly to each point of the liquid food. Technically, a complete PEF treatment system has been successfully developed and is ready to be tested using the actual microorganism.

\section{Data Availability}

No data were used to support this study.

\section{Conflicts of Interest}

The authors declare that there are no conflicts of interest regarding the publication of this paper.

\section{Acknowledgments}

The authors would like to thank Universiti Teknologi Malaysia (UTM), for the use of facilities and funding by awarding research grants UTM-TDR 46 under vote $07 \mathrm{G} 60$ and UTM-TDR 46.3 under vote 06G14 from the Research Management Centre UTM and Malaysia Ministry of Higher Education (MOHE).

\section{References}

[1] S. J. Beebe, P. M. Fox, L. J. Rec, E. L. K. Willis, and K. H. Schoenbach, "Nanosecond, high-intensity pulsed electric fields induce apoptosis in human cells," The FASEB Journal, vol. 17, no. 11, 2003.

[2] S. B. Dev, D. P. Rabussay, G. Widera, and G. A. Hofmann, "Medical applications of electroporation," IEEE Transactions on Plasma Science, vol. 28, no. 1, 2000.

[3] J. Gehl, "Electroporation: theory and methods, perspectives for drug delivery, gene therapy and research," Acta Physiologica Scandinavica, vol. 177, no. 4, 2003.

[4] R. Heller, J. Schultz, M. L. Lucas et al., "Intradermal delivery of interleukin-12 plasmid DNA by in vivo electroporation," DNA and Cell Biology, vol. 20, no. 1, 2002.

[5] L. M. Mir, M. F. Bureau, J. Gehl et al., "High-efficiency gene transfer into skeletal muscle mediated by electric pulses," Proceedings of the National Academy of Sciences, vol. 96, no. 8, 2002.

[6] K. J. Müller, V. L. Sukhorukov, and U. Zimmermann, "Reversible electropermeabilization of mammalian cells by highintensity, ultra-short pulses of submicrosecond duration," Journal of Membrane Biology, vol. 184, no. 2, 2001.

[7] H. Potter, "Electroporation in biology: methods, applications, and instrumentation," Analytical Biochemistry, vol. 174, no. 2, 1988.

[8] D. P. Rabussay, G. S. Nanda, and P. M. Goldfarb, "Enhancing the effectiveness of drug-based cancer therapy by electroporation (electropermeabilization)," Technology in Cancer Research and Treatment, vol. 1, no. 1, 2002.

[9] K. H. Schoenbach, R. P. Joshi, R. H. Stark, F. C. Dobbs, and S. J. Beebe, "Bacterial decontamination of liquids with pulsed electric fields," IEEE Transactions on Dielectrics and Electrical Insulation, vol. 7, no. 5, 2000.

[10] K. H. Schoenbach, R. H. Stark, S. J. Beebe, and E. S. Buescher, "Bioelectrics-new applications for pulsed power technology," in Proceedings of the PPPS-2001 Pulsed Power Plasma Science 2001, Las Vegas, NV, USA, June 2001.

[11] L. Zhang, "Electroporation and electrofusion in cell biology," Bioelectrochemistry and Bioenergetics, Elsevier, Ajax, Amsterdam, 2002.

[12] B. Hargrave, H. Downey, R. Strange et al., "Electroporationmediated gene transfer directly to the swine heart," Gene Therapy, vol. 20, no. 2, 2013.

[13] W. Zhao, R. Yang, and M. Wang, "Cold storage temperature following pulsed electric fields treatment to inactivate sublethally injured microorganisms and extend the shelf life of green tea infusions," International Journal of Food Microbiology, vol. 129, no. 2, 2009.

[14] N. F. Kasri and M. A. M. Piah, "Development of compact pulse generator with adjustable pulse width for pulse electric field treatment technology," International Journal of Power Electronics and Drive Systems, vol. 9, no. 2, 2018.

[15] O. G. M. Khan and A. H. El-Hag, "Biological cell electroporation using nanosecond electrical pulses," in Proceedings of 
the 2011 1st Middle East Conference on Biomedical Engineering, MECBME, Sharjah, UAE, February 2011.

[16] B. I. Morshed, M. Shams, and T. Mussivand, "Investigation of low-voltage pulse parameters on electroporation and electrical lysis using a microfluidic device with interdigitated electrodes," IEEE Transactions on Biomedical Engineering, vol. 61, no. 3, 2014.

[17] G. Pucihar, J. Krmelj, M. Reberšek, T. B. Napotnik, and D. Miklavčič, "Equivalent pulse parameters for electroporation," IEEE Transactions on Biomedical Engineering, vol. 58 , no. $11,2011$.

[18] R. Sundararajan, R. Rajendran, S. S. Shahid et al., "Effect of irreversible electroporation on cancer cells," in Proceedings of the Annual Report Conference on Electrical Insulation and Dielectric Phenomena, IEEE, Cancun, Mexico, pp. 164-167, October 2011.

[19] Z. Yu, X. Zhang, P. Ren, M. Zhang, and J. Qian, “Therapeutic potential of irreversible electroporation in sarcoma," Expert Review of Anticancer Therapy, vol. 12, no. 2, 2012.

[20] A J. H. Sale and W. A. Hamilton, "Effects of high electric fields on microorganisms: I: killing of bacteria and yeasts," Biochimica et Biophysica Acta (BBA)-General Subjects, vol. 148, no. 3, 1967.

[21] S. Toepfl, "Pulsed electric field food processing -industrial equipment design and commercial applications," Stewart Postharvest Review, vol. 8, no. 2, 2012.

[22] A. Golberg, C. S. Rae, and B. Rubinsky, "Listeria monocytogenes cell wall constituents exert a charge effect on electroporation threshold," Biochimica et Biophysica Acta Biomembranes, vol. 1818, no. 3, 2012.

[23] S. Guyot, E. Ferret, J. B. Boehm, and P. Gervais, "Yeast cell inactivation related to local heating induced by low-intensity electric fields with long-duration pulses," International Journal of Food Microbiology, vol. 113, no. 2, 2007.

[24] C. N. Haas and D. Aturaliye, "Semi-quantitative characterization of electroporation-assisted disinfection processes for inactivation of giardia and cryptosporidium," Journal of Applied Microbiology, vol. 86, no. 6, 1999.

[25] S. Haberl, M. Jarc, A. Štrancar, M. Peterka, D. Hodžić, and D. Miklavčič, "Comparison of alkaline lysis with electroextraction and optimization of electric pulses to extract plasmid DNA from Escherichia coli," Journal of Membrane Biology, vol. 246, no. 11, 2013.

[26] V. O. Marquez, G. S. Mittal, and M. W. Griffiths, "Destruction and inhibition of bacterial spores by high voltage pulsed electric field," Journal of Food Science, vol. 62, no. 2, 2006.

[27] T. Ohshima, K. Sato, H. Terauchi, and M. Sato, "Physical and chemical modifications of high-voltage pulse sterilization," Journal of Electrostatics, vol. 42, no. 1, 1997.

[28] S. K. Yeo and M. T. Liong, "Effect of electroporation on viability and bioconversion of isoflavones in mannitol-soymilk fermented by lactobacilli and bifidobacteria," Journal of the Science of Food and Agriculture, vol. 93, no. 2, 2013.

[29] M. K. Žgalin, D. Hodžić, M. Reberšek, and M. Kandušer, "Combination of microsecond and nanosecond pulsed electric field treatments for inactivation of Escherichia coli in water samples," The Journal of Membrane Biology, vol. 245, no. 10, pp. 643-650, 2012.

[30] C. Gusbeth, W. Frey, H. Volkmann, T. Schwartz, and H. Bluhm, "Pulsed electric field treatment for bacteria reduction and its impact on hospital wastewater," Chemosphere, vol. 75, no. 2, 2009.

[31] J. Mosqueda-Melgar, R. M. Raybaudi-Massilia, and O. Martín-Belloso, "Influence of treatment time and pulse frequency on Salmonella enteritidis, Escherichia coli and Listeria monocytogenes populations inoculated in melon and watermelon juices treated by pulsed electric fields," International Journal of Food Microbiology, vol. 117, no. 2, 2007.

[32] F. Noci, M. Walkling-Ribeiro, D. A. Cronin, D. J. Morgan, and J. G. Lyng, "Effect of thermosonication, pulsed electric field and their combination on inactivation of Listeria innocua in milk," International Dairy Journal, vol. 19, no. 1, 2009.

[33] J. C. Park, M. S. Lee, D. H. Lee et al., "Inactivation of bacteria in seawater by low-amperage electric current," Applied and Environmental Microbiology, vol. 69, no. 4, 2003.

[34] A. Rieder, T. Schwartz, K. Schön-Hölz et al., "Molecular monitoring of inactivation efficiencies of bacteria during pulsed electric field treatment of clinical wastewater," Journal of Applied Microbiology, vol. 105, no. 6, 2008.

[35] G. Saulis, "Electroporation of cell membranes: the fundamental effects of pulsed electric fields in food processing," Food Engineering Reviews, vol. 2, no. 2, 2010.

[36] S. Schilling, S. Schmid, H. Jäger et al., "Comparative study of pulsed electric field and thermal processing of apple juice with particular consideration of juice quality and enzyme deactivation," Journal of Agricultural and Food Chemistry, vol. 56, no. $12,2008$.

[37] K. Uemura and S. Isobe, "Developing a new apparatus for inactivating Bacillus subtilis spore in orange juice with a high electric field AC under pressurized conditions," Journal of Food Engineering, vol. 56, no. 4, 2003.

[38] H. Vega-Mercado, O. Martín-Belloso, F. J. Chang, G. V. Barbosa-Ccanovas, and B. G. Swanson, "Inactivation of Escherichia coli and Bacillus subtilis suspended in pea soup using pulsed electric fields," Journal of Food Processing and Preservation, vol. 20, no. 6, 1996.

[39] M. C. Vernhes, A. Benichou, P. Pernin, P. A. Cabanes, and J. Teissié, "Elimination of free-living amoebae in fresh water with pulsed electric fields," Water Research, vol. 36, no. 14, 2002.

[40] Q. Xin, X. Zhang, and L. Lei, "Inactivation of bacteria in oilfield reinjection water by pulsed electric field (PEF) process," Industrial and Engineering Chemistry Research, vol. 47, no. 23, 2008.

[41] N. Grimi, A. Dubois, L. Marchal, S. Jubeau, N. I. Lebovka, and E. Vorobiev, "Selective extraction from microalgae nannochloropsis sp. using different methods of cell disruption," Bioresource Technology, vol. 153, 2014.

[42] T. Ohshima, Y. Hama, and M. Sato, "Releasing profiles of gene products from recombinant Escherichia coli in a high-voltage pulsed electric field," Biochemical Engineering Journal, vol. 5, no. 2, 2000.

[43] M. Suga and T. Hatakeyama, "Gene transfer and protein release of fission yeast by application of a high voltage electric pulse," Analytical and Bioanalytical Chemistry, vol. 394, no. 1, 2009.

[44] Y. Zhan, V. A. Martin, R. L. Geahlen, and C. Lu, "One-step extraction of subcellular proteins from eukaryotic cells," Lab on a Chip, vol. 10, no. 16, 2010.

[45] H. L. M. Lelieveld, S. Notermans, and S. W. H. D.e Haan, Food Preservation by Pulsed Electric Fields, Woodhead Publishing, Cambridge, UK, 1st edition, 2007.

[46] M. Reberšek, D. Miklavčič, C. Bertacchini, and M. Sack, "Cell membrane electroporation-part 3: the equipment," IEEE Electrical Insulation Magazine, vol. 30, no. 3, 2014.

[47] M. Rebersek and D. Miklavčič, "Concepts of electroporation pulse generation and overview of electric pulse generators for cell and tissue electroporation," in Advanced Electroporation 
Techniques in Biology and MedicineTaylor \& Francis Group, Oxfordshire UK, 2010.

[48] M. Puc, S. Čorović, K. Flisar, M. Petkovšek, J. Nastran, and D. Miklavčič, "Techniques of signal generation required for electropermeabilization," Bioelectrochemistry, vol. 64, no. 2, pp. 113-124, 2004.

[49] R. J. Baker and B. P. Johnson, "Series operation of power mosfets for high-speed, high-voltage switching applications," Review of Scientific Instruments, vol. 64, no. 6, 1993.

[50] R. J. Baker and B. P. Johnson, "Stacking power mosfets for use in high speed instrumentation," Review of Scientific Instruments, vol. 63, no. 12, 1992.

[51] W. Jiang, "Fast high voltage switching using stacked MOSFETs," IEEE Transactions on Dielectrics and Electrical Insulation, vol. 14, no. 4, pp. 947-950, 2007.

[52] J. Sun and P. Wang, "A cmos short pulse generator with a high-voltage stacked mosfet switch," in Proceedings of the IEEE 57th International Midwest Symposium on Circuits and Systems (MWSCAS), College Station, TX, USA, August 2014.

[53] H. Jambari, N. A. Azli, and M. A. M. Piah, "Comparison of pulsed electric field generation techniques for microbial inactivation application," Journal of Theoretical and Applied Information Technology, vol. 33, 2011.

[54] B. L. Qin, G. V. Barbosa-Canovas, B. G. Swanson, P. D. Pedrow, and R. G. Olsen, "Inactivating microorganisms using a pulsed electric field continuous treatment system," IEEE Transactions on Industry Applications, vol. 34, no. 1, 1998. 